\begin{tabular}{lllllllllllllllllllllllllllllllll}
\hline$R$ & $E$ & $V$ & I & S & T & A & D & E & E & S & T & U & D & I & O & S & I & N & T & E & R & N & A & C & I & O & N & A & L & E & S
\end{tabular}

\title{
América Latina hoy en 12 preguntas y 120 sugerencias
}

El Instituto de Estudios Internacionales, con el patrocinio de la Facultad de Derecho de la Universidad de Chile, la Corporación de Estudios Internacionales y la Academia de Ciencias Sociales, Políticas y Morales del Instituto de Chile, organizó un ciclo de conferencias que tituló "América Latina hoy en 12 preguntas y 120 sugerencias", para examinar los problemas que enfrenta la región y recopilar propuestas de solución.

Como referencia motivacional, el ciclo partió de la base de que América Latina llegó al término del siglo con optimismo cauteloso. Atrás quedaba la década perdida de los años ochenta y, en los noventa, los principales instrumentos jurídicos incorporaban la cláusula democrática como compromiso formal de que no habría vuelta al pasado Había, sí, algunas señales inquietantes en algunos escenarios políticos, que apuntaban a tendencias populistas susceptibles de reactivación. También había conciencia sobre la doble faz de la globalización. Sin embargo, paulatinamente comenzó a percibirse que el optimismo decaía y que, según los indicadores ad usum, la región volvía a estar en crisis. Se trataba, entonces, de indagar las razones profundas de esta recurrencia y de procesar nuevos diagnósticos.

La dirección del ciclo, que se realizó en el Aula Magna de la Escuela de Derecho de la Universidad de Chile entre el 3 y el 29 de julio de 2002, correspondió al profesor Francisco Orrego Vicuña, y su coordinación académica a la profesora Lillyan Jara Urrutia.

En ese marco, diplomáticos, académicos y expertos abordaron cada uno un tema diferente, relacionado con la región en general y algunos países en particular, sintetizando en diez medidas finales sus sugerencias para mejorar la situación. Al ministro del 
América Latina

hoy en 12

preguntas y 120

sugerencias
Interior, José Miguel Insulza, le correspondió iniciar el ciclo con una reflexión sobre la factibilidad de una visión renovadora para orientar el futuro de América Latina. Como ex embajador en México, el director de la Dirección de Planificación del Ministerio de Relaciones Exteriores, Embajador Carlos Portales, tuvo a su cargo examinar la nueva relación entre el país y los Estados Unidos. El profesor, escritor y diplomático José Rodríguez Elizondo analizó la situación actual del Perú en su contexto histórico, enfatizando la necesidad de una mejor relación con Chile. El Ministro Secretario General de Gobierno y ex Embajador en Brasil, Heraldo Muñoz, se refirió al rol que está jugando ese país, siempre estratégico por su peso específico en la región. La conferencia del profesor de la Pontificia Universidad Católica, Vittorio Corbo, tuvo el sugestivo título de "¿Puede Argentina salir del corralito sin pasar por el corralón?”. El ex embajador en los Estados Unidos, John Biehl, analizó la crisis de Colombia evocando la guerra de Vietnam. El profesor Jorge Heine examinó las perspectivas de reconciliación nacional y reinserción internacional de Cuba, después de Fidel Castro. El caso de Venezuela, como test de la Carta Democrática Interamericana, fue analizado por el profesor Walter Sánchez. El Director del Centro de Estudios e Investigaciones Militares (CESIM), General José Miguel Piuzzi, se refirió a la compatibilidad de la paz con la pobreza en la región. El profesor del Instituto de Economía de la Pontificia Universidad Católica, Felipe Larraín, enfrentó la consulta sobre la relación crecimiento-estancamiento en las economías de la región. El presidente del Banco Central, Carlos Massad, realizó una detallada exposición sobre la eventual excepcionalidad de Chile ante la crisis regional. Cerró el ciclo la ministra de Relaciones Exteriores, María Soledad Alvear, abordando el tema "¿Tiene América Latina un papel propio en la comunidad internacional?".

Las exposiciones mencionadas suscitaron el interés de un numeroso público de académicos, especialistas y alumnos. Al término de cada conferencia, éstos participaron en un debate que enriqueció el contenido del ciclo. Así, a la tarea de formular diez sugerencias, que correspondió a cada expositor, siguió la de reflexionar colectivamente sobre ellas.

El ciclo demostró, en definitiva, que la comunidad académica chilena está consciente del momento regional que se vive. El mis- 
mo que implica decisiones políticas del mayor nivel para acelerar y profundizar los proyectos de integración en largo trámite.

Finalmente, entre las sugerencias planteadas por los expositores, pueden mencionarse las siguientes:

- Globalización y apertura no funcionan solas: al Estado le corresponde determinar el orden de las prioridades, considerando el interés nacional (Insulza).

-Junto con generar crecimiento, la apertura económica ha producido mayor diferenciación y por ello es preciso velar por la continuidad y perfeccionamiento del proceso de reformas (Portales).

- Los gobiernos de Chile y Perú podrían incentivar el intercambio del mejor y del peor programa de la televisión abierta de cada país, lo que contribuiría a una percepción realista y actualizada de sus respectivas sensibilidades (Rodríguez).

- A menudo olvidamos que Brasil es la octava o novena potencia económica del mundo y que seguirá siendo vital para Chile y el resto de los países de América Latina (Muñoz).

- Para la reconstrucción de Argentina se requerirá, entre otras cosas, un programa monetario ordenado que asegure una inflación relativamente controlada (Corbo).

- Para proceder con realismo, hay que mantener la serenidad ante las dificultades y resaltar las cosas que nos unen como chilenos y no las que nos separan (Massad)

- En el caso de Colombia, hay que hacer una política de fronteras con los cinco países limítrofes que implique un modelo de desarrollo sustentable a fin de que los puntos de encuentro se transformen en esfuerzo de desarrollo conjunto (Biehl).

- Para bien o para mal, la comunidad cubana en el exilio seguirá desempeñando un papel clave en el futuro del país (Heine).

- América Latina es un ecosistema globalizado y hay que impulsar un modelo de desarrollo perdurable e impregnado de un contrato generacional entre quienes tienen responsabilidades y quienes las tendrán en el futuro (Alvear). 